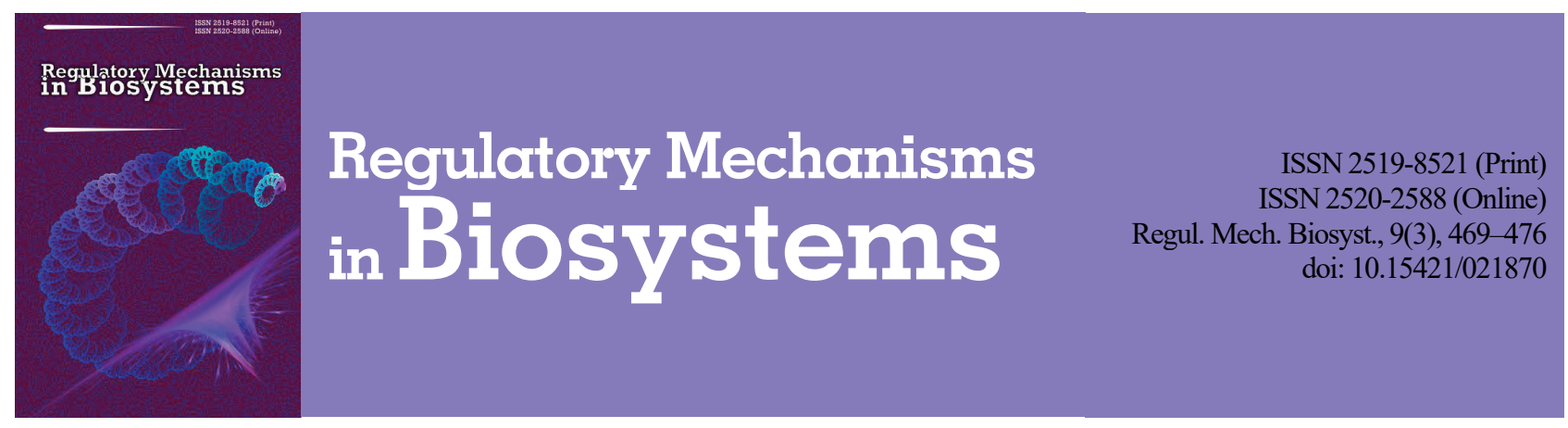

\title{
Enzyme-like activity of nanomaterials
}

\author{
S. I. Tsekhmistrenko*, V. S. Bityutskyy*, O. S. Tsekhmistrenko*, V. M. Polishchuk*, \\ S. A. Polishchuk*, N. V. Ponomarenko*, Y. O. Melnychenko*, M. Y. Spivak** \\ *Bila Tserkva National Agrarian University, Bila Tserkva, Ukraine \\ **Zabolotny Institute of Microbiology and Virology of NAS of Ukraine, Kyiv, Ukraine
}

Article info

Received 11.06.2018

Received in revised form 07.07.2018

Accepted 08.07.2018

Bila Tserkva National Agrarian University, Soborna ploshcha, 8/1 Bila Tserkva, 09100, Ukraine. Tel: + 38-045-635-12-88

Zabolotny Institute of Microbiolog and Virology of NAS of Ukraine,

Akad. Zabolotny st., 154 ,

Kyiv, 03680, Ukraine.

Tel.: +38-068-034-48-48

E-mail:

svetlana.tsehmistrenko@gmail.com

Tsekhmistrenko, S. I., Bityutskyy, V. S., Tsekhmistrenko, O. S., Polishchuk, V. M., Polishchuk, S. A., Ponomarenko, N. V., Melnychenko, Y. O., \& Spivak, M. Y. (2018). Enzyme-like activity of nanomaterials. Regulatory Mechanisms in Biosystems, 9(3), 469-476. doi:10.15421/021870

In modern conditions, nanomaterials, especially nanoparticles of metals and nonmetals, are increasingly used in various industries. Due to their unique properties, in particular, the ability of nanoparticles to exhibit an enzyme-like effect they are widely used in biology, medicine, biotechnology, the food industry and agriculture. Important advantages of nanoparticles are their size, which enables specific properties to be present: their large surface area, the ability to transfer molecules and the ability to protect them from degradation and release over a long time, the location of action and the specificity of interaction with biological structures. Nanoparticles play a special role in the processes of neutralizing the active forms of oxygen. It has been established that a number of nanoparticles, in particular, Fe, Mn, Zn, Ce, Si and Se oxides, have an enzyme-like activity mimicking that of some enzymes. By changing the degree of oxidation, these particles can regenerate and continuously catalyze the reaction of neutralizing superoxide anion radicals, thus fulfilling the function of SOD and being the first link in protecting tissues and cells from oxidative stress in physiological and pathological conditions. It is proved that nanoparticles $\mathrm{Mn}_{3} \mathrm{O}_{4}, \mathrm{Fe}_{3} \mathrm{O}_{4}$, $\mathrm{Co}_{3} \mathrm{O}_{4}, \mathrm{CeO}_{2}, \mathrm{LaCoO}_{3}$ and other elements can effectively dispose of hydrogen peroxide and other peroxides, showing catalaselike and peroxidase-like activity. Nanozymes are characterized that exhibit the activity of oxidases, peroxidases and phosphatase. The prospect of using mimetics for complex in vitro analyzes of high-sensitivity biomarker disease detection is shown. The possibility of effective multi-use of nanoparticles as antioxidants is indicated. There are good prospects for further research on properties and the use of polyfunctional particles that are easily synthesized, reliable and inexpensive. More work is needed to determine the interaction of enzymomimetics with biological molecules such as proteins, carbohydrates and lipids, and also to take into account the peculiarities of their metabolism, clearance, degradation, biocompatibility and side effects, since individual nanoparticles have the potential to be deposited in separate organs.

Keywords: mimetics; superoxide dismutase; catalase; oxidase; peroxidase; phosphatase.

\section{Introduction}

The 21st century is considered to be the period of global usage of nanotechnology, which deals with a set of theoretically sound and practical methods of research, analysis and synthesis, as well as the production and use of products with a predictable atomic structure through controlled manipulation of individual atoms and molecules (Gordon et al., 2007). Due to the extremely small dimensions (up to $100 \mathrm{~nm}$ ) and the large surface area per unit volume, nanomaterials have specific chemical, physical and biological properties that are useful for many new applications. Many nanoparticles (NPs) have been found to exhibit enzymatic activity and are potentially capable of being used in various industries, particularly in the food industry, pharmacy, and biotechnology. The creation of artificial enzymes simulating the complexity and functioning of natural systems is one of the greatest achievements of the last two decades.

\section{Use of nanoparticles}

Rapid development of nanotechnology around the world has created numerous catalytically active nanomaterials (Cormode et al., 2018). Currently, nanomaterials of different origin are used in biology, medicine and biotechnology (Fig. 1). This category includes nanomaterials with enzyme-mimetic properties, such as nanoparticles of metals and nonmetals, their oxides, magnetic nanoparticles, liposomes, carbon and polymer nanomaterials. They are characterized as a potential alternative to natural enzymes and are widely used in many industries such as immunoassay, biosensorica, pharmaceutical processes, oncotherapy, the food industry, ecology, etc. (Chen et al., 2012, 2014; Fu, 2014; Lu et al., 2015; Li \& Zhang, 2016). This demonstrates the great importance and commercial interest of using nanomaterials as enzyme mimetics. Compared to enzymes of natural origin, agonists or mimetics on the basis of nanomaterials can change catalytic activity, are stable in harsh conditions, their production is relatively easy and economically justified (Cheng et al., 2015). The cyclic action of nanoparticles and the possibility of recovery without significant loss in subsequent cycles of catalytic activity makes them unique compounds (Wei \& Wang, 2013). In addition, the surface of nanomaterials, unlike natural enzymes which have only one active site in a molecule, may have more catalytic centers (Liu et al., 2015; Gao et al., 2017). These enzyme mimetics are of great importance in practice (Gordon et al., 2007; Wei \& Wang, 2013; Lin et al., 2014; Xu et al., 2014).

The basic requirements for nanoparticles regarding their use in biology and medicine are low toxicity or absence of it, high biocompatibility, biodegradational property and the ability to be removed from the organism naturally (Fu, 2014; Kozik et al., 2016; Bityutskyy et al., 2017; Chekman et al., 2017). 
The catalytic activity of nanoparticles and the ability to inactivate active forms of oxygen can be used to simulate the catalytic activity of natural enzymes. Different nanoparticles have been studied to date, and their enzymomimetic activity, in particular superoxide dismutase, oxidaselike, peroxidase-like, catalase- and phosphatase-like, have been determined (He et al., 2014; Cormode et al., 2018).

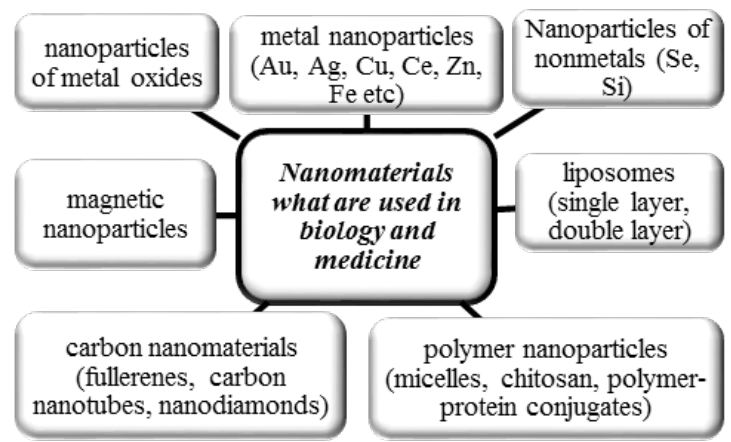

Fig. 1. Nanomaterials used in biology and medicine

\section{General characteristics of mimetics}

Agonists or mimetics are compounds that imitate the action of other substances, being similar to the ones formed in the organism (enzymes, hormones, mediators). Cell receptors react to mimetics as a substance which they interact with (Singh, 2016). According to physical and chemical properties, mimetics are similar to natural signaling molecules, but they have a number of important qualities (Fig. 2).

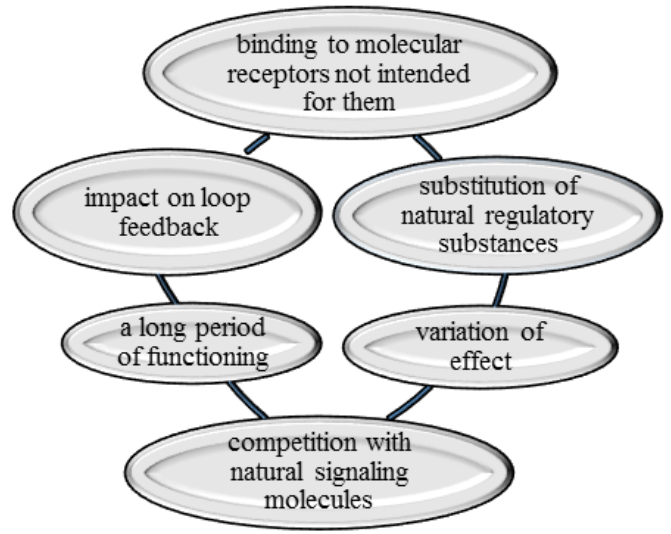

Fig. 2. Properties of mimetic enzymes

They bind to molecular receptors not intended for them, and substitute natural regulatory substances. Mimetics can act more strongly or weakly than the compounds that they replace, that is, their impact varies. They can compete with natural signaling molecules for binding to receptors (by concentration and affinity). The period of functioning of the mimetics in the unchanged state of the organism and the time of binding to the receptors are different from natural compounds. Formation in the body of its own regulatory substances due to the feedback between the concentration of regulators and their production is conditioned by the presence of mimetics (Chekman et al., 2017).

The term "nanozymes" was introduced for nanomaterials with their own enzyme-like activity to distinguish these nanocomplexes from immobilized enzymes (Wei \& Wang, 2013). The development of highly effective non-protein analogues of enzymes is an relevant task for modern biology, biotechnology, medicine and agriculture (Dong et al., 2012; Bityutskyy et al., 2017). Currently, several types of artificial enzymes have been created to replace natural analogues (Kozik et al., 2016; Nelson et al., 2016; Wang et al., 2017).

Natural enzymes and mimetics have many properties in common: they accelerate the chemical reactions and can regenerate (Kozik et al., 2016; Chekman et al., 2017). Natural enzymes, unlike the artificial ones, require special environmental conditions, in particular a certain temperature and $\mathrm{pH}$ (Grulke et al., 2014). Such unique properties of nanomaterials can be used for the prevention, diagnosis and treatment of diseases. Many nanomaterials have powerful antioxidant properties that can potentially act as inhibitors of active forms of oxygen. However, it has also been proven that certain nanomaterials have prooxidant properties that contribute to the formation of active forms of oxygen, which can lead to the formation of oxidative stress, which is known to promote the development of various pathologies (Amani et al., 2017; Sims et al., 2017). One of the important features of nanoenzymes compared to the natural enzymes and other mimetics is that their activity can be regulated by altering the structure, size, surface modification, introduction of protective coverings, etc. (Liu et al., 2015; Kozik et al., 2016; Fa et al., 2018). A relationship between catalytic activity, therapeutic efficiency and biocompatibility of particular mimetics has been determined (Cormode et al., 2018). It was found that the smaller are the particles, the higher is their catalytic activity. This phenomenon is conditioned by the fact that smaller nanoparticles have a larger surface area for interaction with the substrate. This indicates the possibility of synthesizing nanoparticles with a particular activity and properties (Gao et al., 2017). The enzyme-mimetic activity of nanomaterials is influenced by several factors, in particular, their chemical composition, surface charge, particle size, and surface covering (Sharpe et al., 2011; Samuel et al., 2014; Verma, 2014; Sandhir et al., 2015; Cîrcu et al., 2016; Shah et al., 2017). However, both the positive and the toxic effects of NPs may be differrent, since the synthesis method, the choice of stabilizers which cover the particles, can lead to a different biological effect (Estevez et al., 2017). It is important to understand which physical-chemical properties correlate with biological activity, and are critical for determining the conditions that contribute to the positive effect and for determining the circumstances which lead to formation of toxic properties.

There is a prospect of using nanomaterials for medical and industrial purposes (Armstrong et al., 2013; Sandhir et al., 2015). It is believed that their significant activity provides more effective neutralization of various types of active forms of oxygen (Sandhir et al., 2015). Recently, antioxidant activity was determined for various metallic nanocomposites such as gold (Esumi et al., 2003; BarathManiKanth et al., 2010), platinum (Kajita et al., 2007; Kim et al., 2008; Moglianetti et al., 2016), iron (Paul et al., 2009; Szekeres et al., 2014; Toth et al., 2014; Shah et al., 2017), nickel (Saikia et al., 2010), cerium (Kim et al., 2012) and yttrium (Schubert et al., 2006). Nanoparticles (NPs) of metal oxides are intensively studied (Kozik et al., 2016; Tsekhmistrenko et al., 2018). They are successfully used in the treatment of a number of pathologies, have high colloidal resistance and biocompatibility (Grillone et al., 2017).

Nanoparticles with their antioxidant activity conditioned by the ability to exhibit enzyme-mimetic action, can be promising therapeutic agents that can be used for targeted drug delivery (Morry et al., 2017). However, with nanoparticles, one should take into account such issues as metabolism, clearance, degradation, biocompatibility and side effects, since individual nanoparticles have the potential for prolonged maintenance in the organs, in particular, the liver and spleen (Cormode et al., 2018). The interaction of nanoparticles with the local environment plays an important role in their distribution and long-term stability (Dhall et al., 2017).

\section{Nanomaterials as SOD mimetics}

Superoxide dismutase is an enzyme that functions for the catalytic conversion of a superoxide radical to oxygen and hydrogen peroxide. The catalytically active metal of this enzyme can be $\mathrm{Cu}, \mathrm{Fe}, \mathrm{Mn}$.

A superoxide radical which is formed predominantly in mitochondria and, when protons are added is capable of being converted into hydroperoxide (Fig. 3), is one of the most destructive forms of oxygen (Lushchak, 2015; Wang et al., 2017). It is known that SOD inactivates superoxide anion in two stages with formation of hydrogen peroxide and oxygen (Shin et al., 2009). In this case, the general reaction of superoxide anion dismutation for nanoparticles also includes two stages (Korsvik et al., 2007).

SOD-like activity is typical for various metal oxide nanoparticles, in particular nano- $\mathrm{TiO}_{2}$ (Zheng et al., 2017), $\mathrm{ZnO}$ (Li et al., 2018), 
$\mathrm{Fe}_{3} \mathrm{O}_{4}$ (Khedri et al., 2018), NiO-NPs (Faisal et al., 2013), $\mathrm{Mn}_{3} \mathrm{O}_{4}$ (Yao et al., 2018), $\mathrm{LaCoO}_{3}$ (Wang et al., 2017), CeNPs (Batinić-Haberle et al., 2010; Heckert et al., 2008), Pt (Wei \& Wang, 2013), Au (Lin et al., 2014) and nonmetals: $\mathrm{SiO}_{2}$ (Farhangi-Abriz et al., 2018; Soares et al., 2018) and Se (Guo et al. 2016). These mimetics provide considerable interest, as they are characterized by increased stability, multifunctionnality and regulated activity.

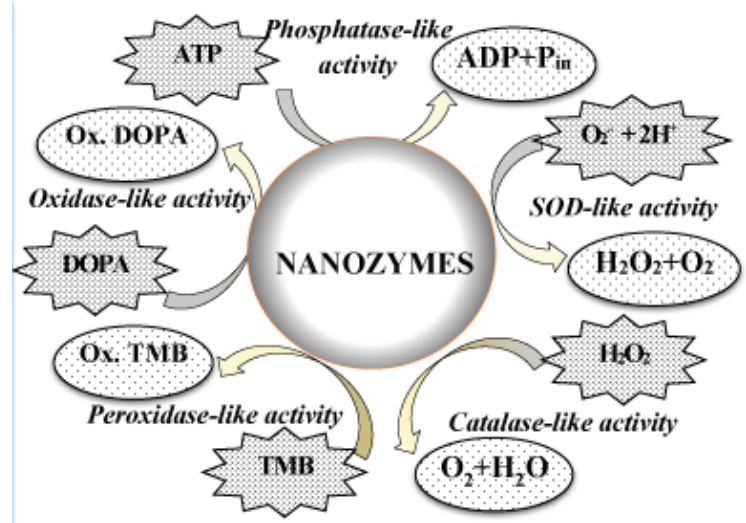

Fig. 3. Enzyme-like properties of nanomaterials: $\operatorname{TMB}$ (3,3,5,5-tetramethylbenzidine), DOPA (dihydroxyphenylalanine) (adopted from Singh, 2017)

One of the first superoxide dismutase activities determined was for cerium dioxide nanoparticles (Korsvik et al., 2007; Singh, 2016). In the case of superoxide anion dismutration, the formation of hydrogen peroxide and transitional compound - cerium hydroperoxide $\mathrm{Ce}(\mathrm{OOH})(\mathrm{OH})_{3}$ on the surface of the nanodispersed cerium dioxide occurs, ie, three reactions actually occur (Batinić-Haberle et al., 2010):

Oxidation of $\mathrm{O}_{2}^{-}-\overline{\mathrm{e}} \rightarrow \mathrm{O}_{2}$;

Restoration of $\mathrm{O}^{2-}+\overline{\mathrm{e}}+2 \mathrm{H}^{+} \rightarrow \mathrm{H}_{2} \mathrm{O}_{2}$;

Oxidation-reduction $\mathrm{Ce}^{3+}+4 \mathrm{H}_{2} \mathrm{O} \leftrightarrow \mathrm{Ce}(\mathrm{OH})_{4}+4 \mathrm{H}^{+}+\overline{\mathrm{e}}$.

The treatment of cerium nanoparticles with $\mathrm{H}_{2} \mathrm{O}_{2}$ causes a complete loss of SOD-like activity, but after a certain period of time, the activity is restored, which confirms the process of spontaneous regeneration of the nanoparticle surface (in relation to oxygen non-stoichiometry) and recovery to trivalent cerium (Gil et al., 2017; Baldim et al., 2018). The activity of nanoparticles depends on their size. NPs, the size of which is $3-5 \mathrm{~nm}$, more intensively inactivate superoxide anion than larger nanoparticles $(5-8 \mathrm{~nm})$. The effectiveness of nanocerium to act as a SOD mimetic is proportional to the concentration of $\mathrm{Ce}^{3+}$ ions on the surface of particles (Nelson et al., 2016). The presence of other ions, in particular titanium ions, inhibits this activity (Zhu et al., 2012). SOD-like activity of nanoparticles depends on the ionic composition of the solution (McCormack et al., 2014). During the action of phosphate ions, phosphorylation of the surface of particles occurs, which reduces their ability to manifest the functions of SOD and catalase.

\section{Nanomaterials as catalase mimetics}

Along with superoxide radionuclide, hydrogen peroxide is also an active form of oxygen that is neutralized due to catalase. It was determined that a number of nanoparticles effectively protect the cells and tissues from the toxic effects of $\mathrm{H}_{2} \mathrm{O}_{2}$ (Grinko et al., 2015; Wang et al., 2017) and other peroxides (Sun et al., 2017).

Nanoparticles of $\mathrm{Mn}_{3} \mathrm{O}_{4}$ (Yao et al., 2018), $\mathrm{Fe}_{3} \mathrm{O}_{4}, \mathrm{Co}_{3} \mathrm{O}_{4}$ and $\mathrm{CeO}_{2}$ (Wei \& Wang, 2013), $\mathrm{LaCoO}_{3}$ (Wang et al., 2017), NiO-NPs (Faisal et al., 2013), $\mathrm{Au}$ (Lin et al., 2014) simulate the activity of catalase. In conditions of physiological reactions, including the substrate, the optimal values of $\mathrm{pH}$ and temperature, some nanoparticles, particularly of ferrum oxide, demonstrate catalase- and peroxidase-like activity (Gao et al., 2017). The $\mathrm{Fe}_{2} \mathrm{O}_{3}$ and $\mathrm{Fe}_{3} \mathrm{O}_{4}$ nanoparticles decompose $\mathrm{H}_{2} \mathrm{O}_{2}$ in a neutral and alkaline medium, but it was found that $\mathrm{Fe}_{3} \mathrm{O}_{4}$ was characterized by higher catalase mimetic activity. Similarly to peroxidase-like activity, the $\mathrm{pH}$ range is essential in the effectiveness of this reaction (Chen et al., 2012; Gao et al., 2017). Singh et al. (2017) reported that the ability of graphenes to simulate the catalase function at $\mathrm{pH}>7.2$. The mechanism of mimetic action of nanoparticles is complex and remains incompletely studied. Grinko et al. (2015) mention that the process of decomposition of $\mathrm{H}_{2} \mathrm{O}_{2}$ by nanoparticles is similar to the mechanism of catalase activity. The intensity of the catalase-mimetic activity of nanoparticles of transition metals, in particular cerium, is conditioned by the number of ions of trivalent Ce on their surface (Das et al., 2013; Nelson et al., 2016; Yang et al., 2016). The reactivity of hydrogen peroxide is affected by the size of nanoparticles and surface ligands (Lee et al., 2013; Gil et al., 2017). Small $\mathrm{CeO}_{2}$ nanoparticles, and those containing more oxide, exhibit increased reactivity to $\mathrm{H}_{2} \mathrm{O}_{2}$. Reaction of the decomposition is not hindered by the surface ligand. Concentrations of $\mathrm{Ce}^{3+}$ ions on the surface of $\mathrm{CeO}_{2}$ nanoparticles have a proportional effect on their catalase-like activity (Nelson et al., 2016).

The possibility of effective use and reuse of $\mathrm{CeO}_{2}$ nanoparticles as an antioxidant has been proved. Such effect occurs due to the fact that at first the $\mathrm{Ce}^{3+}$ ions located on the surface of nanoparticles, are oxidized with hydrogen peroxide, forming $\mathrm{Ce}^{4+}$.

At the same time, $\mathrm{H}_{2} \mathrm{O}_{2}$ is irreversibly adsorbed on the surface of hydrated $\mathrm{Ce}^{4+}$ ions, forming cerium perhydroxide. Perhydroxide is decomposed with the formation of oxygen. After using all of the hydrogen peroxide in the system, part of the quaternary cerium ions due to the restoration (recovery) of the crystalline lattice of the nanoparticle returns to the initial Ce ${ }^{3+}$ state (Celardo et al., 2011; Grinko et al., 2015; Kozik et al., 2016). These processes are possible due to the occurrence of oxygen vacancies which contribute to the formation of oxygen non-stoichiometry and increase in the number of cerium atoms with the III degree of oxidation. The set of processes which occurs on the surface of cerium nanoparticles can be represented in the form of a scheme:

$$
\begin{gathered}
\mathrm{NP}-\mathrm{Ce}^{3+}+\mathrm{H}_{2} \mathrm{O}_{2} \rightarrow \mathrm{NP}-\mathrm{Ce}^{4+}=\mathrm{O}+\mathrm{H}_{2} \mathrm{O}, \\
\mathrm{NP}-\mathrm{Ce}^{4+}=\mathrm{O}+\mathrm{H}_{2} \mathrm{O}_{2} \rightarrow \mathrm{NP}-\mathrm{Ce}^{3+}+\mathrm{H}_{2} \mathrm{O}+\mathrm{O}_{2} .
\end{gathered}
$$

Ions of various metals can modify the catalase-like activity of nanoparticles (Tsai et al., 2007). Therefore, in the case of doping into a crystalline lattice of cerium dioxide of zirconium ions, there was observed the activation of the decomposition of hydrogen peroxide, which was directly proportional to the molar $\mathrm{Zr} / \mathrm{Ce}$ ratio. Celardo et al. (2011) mentioned the opposite effect after introducing Samarium ions into the crystalline lattice of CeNPs. The authors observed a monotonic decrease in the speed of decomposition of hydrogen peroxide, which depended on the content of Samaria.

It was determined that nanopolyhedrons with a high concentration of $\mathrm{Ce}^{4+}$ ions contributed to the mimetic activity of catalase, while nanotubes and nanopowders with high concentration of $\mathrm{Ce}^{3+}$ ions increased the mimetic activity of SOD (Naganuma, 2017). These results should be used to construct nanoparticles aimed at enhancing enzyme mimetic activity for therapeutic purposes. It was determined that biomimetic artificial enzymes based on antioxidant $\mathrm{CeO}_{2}$ nanoparticles become luminescent during their $\mathrm{Eu}^{3+}$ doping (Pratsinis et al., 2017).

\section{Nanomaterials as oxidase mimetics}

Over the recent decades, the enzyme-like properties of nanomaterials have been widely studied, but for the most part, attention has been paid to SOD-like, peroxidase- and catalase-like activity of these nanomaterials. Now, research is becoming focused on nanomaterials with oxidase-like properties.

Oxidases are enzymes from the oxidoreductase class, which catalyze the oxidation-recovery reaction, which includes molecular oxygen as an acceptor of electrons. In the course of reactions which are catalyzed by oxidase, the substrate oxidizes by molecular oxygen, forming water, hydrogen peroxide or free oxygen radicals (Singh, 2016). These enzymes catalyze a number of reactions:

Glucose $+\mathrm{O}_{2} \rightarrow$ Gluconic acid $+\mathrm{H}_{2} \mathrm{O}_{2}$ (Glucose oxidase)

Galactose $+\mathrm{O}_{2} \rightarrow 1$,6-Diadehyde $+\mathrm{H}_{2} \mathrm{O}_{2}$ (Galactose oxidase) Alcohol $+\mathrm{O}_{2} \rightarrow$ Aldehyde $+\mathrm{H}_{2} \mathrm{O}_{2}$ (Alcohol oxidase)

Cholesterol $+\mathrm{O}_{2} \rightarrow$ Cholesteon $+\mathrm{H}_{2} \mathrm{O}_{2}$ (Cholesterol oxidase) Choline $\rightarrow$ Betaine $+\mathrm{H}_{2} \mathrm{O}_{2}$ (Choline oxidase)

Recently, research has increasingly focussed on the oxidase-mimetic activity of nanoparticles. The studies by Cao et al. (2017) revealed that 
ruthenium nanoparticles $(\mathrm{Ru})$ exhibit their own oxidase activity, catalyzing the oxidation of tetramethylbenzidine (TMB) and sodium L-ascorbate with dissolved oxygen. Similar activity was demonstrated by $\mathrm{Pt}$ nanoparticles (Deng et al., 2017), Au (He et al., 2011), Ir (Cui et al., 2017), $\mathrm{CoFe}_{2} \mathrm{O}_{4}$ (Zhang et al., 2013), $\mathrm{ZnFe}_{2} \mathrm{O}_{4}$ (Su et al., 2012), $\mathrm{MnO}_{2}$ (Yan et al., 2017), $\mathrm{CeO}_{2}$ (Dalapati, 2017; Estevez et al., 2017), $\mathrm{NiCo}_{2} \mathrm{O}_{4}$ (Song et al., 2018), Se (Guo et al., 2016) and other metals and composites. It was determined that the maximum mimetic activity depends on particular physical parameters. Thus, the nanoparticles of Se exhibited optimal catalytic activity at $\mathrm{pH} 4$ and $30^{\circ} \mathrm{C}$, and the oxidase-like activity was higher as the concentrations increased and the size reduced (Guo et al., 2016). The maximum activity of iridium nanoparticles (IrNP) which were synthesized using sodium citrate and $\mathrm{NaBH}_{4}$, occured at their average diameter of $2.5 \mathrm{~nm}$ (Cui et al., 2017). Chen et al. (2017) reported the first attempt of using graphene nanoparticles (GQD/AgNP hybrids). These NPs demonstrate high oxidase activity and remained stable in neutral media at temperature of up to $60{ }^{\circ} \mathrm{C}$. The doping of $\mathrm{CeO}_{2}$ nanoparticles by titanium caused no reduction in their oxidase mimetic activity, but was accompanied by a change in the shape of the spherical nanostructure (Zhu et al., 2012).

\section{Nanomaterials as peroxidase mimetics}

Peroxidase is an enzyme that catalyzes the oxidation of polyphenols and some aromatic amines with oxygen, hydrogen peroxide or organic peroxides. Peroxidase forms a complex compound with hydrogen peroxide, resulting in peroxide being activated and becoming able to act as an acceptor of hydrogen (Pandey et al., 2017).

$$
2 \mathrm{RH}+\mathrm{H}_{2} \mathrm{O}_{2} \rightarrow 2 \mathrm{R}+2 \mathrm{H}_{2} \mathrm{O}
$$

Peroxidases, as a cofactor in active centers, contain gem, or redoxactive cysteine or selenium (van Bloois et al., 2010). There are several types of peroxidases, such as glutathione peroxidase, myeloperoxidase, haloperoxidase, lactoperoxidase, etc. (Pandey et al., 2017).

Since 2007, when the enzyme-like peroxidase activity of $\mathrm{Fe}_{3} \mathrm{O}_{4}$ nanoparticles was first recorded, over 40 nanomaterials have been identified (Jiang et al., 2018). It was determined that nanomaterials are characterized by peroxidase activity, including high stability and low cost of synthesis (He et al., 2014; Singh, 2016).

Peroxidation activity is characteristic for $\mathrm{Co}_{3} \mathrm{O}_{4}$ nanoparticles (Jia et al., 2016), $\mathrm{Cu}_{2} \mathrm{O}$ (Chen et al., 2012; Guo et al., 2017), $\mathrm{FeS}$ (Dutta et al., 2012), $\mathrm{CeO}_{2}$ (Sun et al., 2017), $\mathrm{Au} / \mathrm{CeO}_{2}$ (Bhagat et al., 2018), $\mathrm{CoFe}_{2} \mathrm{O}_{4}$ (Fan \& Huang, 2012), $\mathrm{BiFeO}_{3}$ (Luo et al., 2010), $\mathrm{MnFe}_{2} \mathrm{O}_{4}$ (Vernekar, et al., 2016), CdS (Garai-Ibabe et al., 2014), FeSe (Dutta et al., 2012), FeTe (Jiang et al., 2013), rhodium (Choleva et al., 2018), $\mathrm{ZnFe}_{2} \mathrm{O}_{4}$ (Zhao et al., 2013), graphene oxide (Vineh et al., 2017), fullerene (Voeikov \& Yablonskaya, 2015) and carbon nanotubes (Wang et al., 2014). This allows them to be applied for immunoassay, glucose detection, protection against free radicals, etc. Significant enzymic activity of such nanoparticles (in the presence of the nucleus and the shell) is maintained at extreme values of $\mathrm{pH}(2-11)$ and high temperature (up to $90{ }^{\circ} \mathrm{C}$ ), which indicates their superiority over natural enzymes.

Antioxidants based on selenium and tellurium can act as mimetics of glutathione peroxidase, can reduce oxidative stress during inflammatory processes and other pathological conditions (Huang et al., 2014; $\mathrm{Lu}$ et al., 2017; Hosnedlova et al., 2018). Nano-Se has a better antioxidant effect than other chemical forms of selenium, at the same time reducing the risk of its toxicity (Wang et al., 2007). The antioxidant properties of SeNPs nanoparticles are more effective compared to other selenium compounds and less toxic than selenomethionine (SeMet).

The internal triple enzyme-mimetic activity of nickel-palladium nanoparticles (NiPd HNPs) (Wang et al., 2016), $\mathrm{LaCoO}_{3}$ was also studied (Wang et al., 2017) and $\mathrm{V}_{6} \mathrm{O}_{13}$ (Li et al., 2018). The multimimetic particles of NiPd and $\mathrm{V}_{6} \mathrm{O}_{13}$ exhibit oxidase-like, peroxidase-like and catalase-like activity, are reliable, inexpensive and easily synthesized. On the basis of oxidase-like and peroxidase-like activity, a colorimetric biosensor was developed to detect glutathione and a fluorescence system for the detection of $\mathrm{H}_{2} \mathrm{O}_{2}$ and glucose. Recently, there was discovered the "hidden talent" of gold to exhibit mimetic activity (Lin et al., 2014). Gold nanoparticles, similarly to the multimimetics, were observed simu- lating peroxidase, nucleases, esterases, glucose oxidases, catalase and superoxide dismutase. The authors mention that these enzyme-like characteristics are conditioned by nanogold itself or functional groups present in the surrounding monolayer.

Zhao et al. (2018) for the first time reported the construction of mesoporous nanostructures based on $\mathrm{Co}_{3} \mathrm{O}_{4}$ for the dispersion of catalytically active sites for the purpose of doping iron nanoparticles (FeNP). Composites (FeNP @ $\mathrm{Co}_{3} \mathrm{O}_{4} \mathrm{HNCs}$ ) have high peroxidase activity, which is significantly higher compared to iron nanoparticles (FeNP) and $\mathrm{Co}_{3} \mathrm{O}_{4}$. The high catalytic activity of FeNP @ $\mathrm{Co}_{3} \mathrm{O}_{4}$ nanoparticles occurs due to its porous-hollow structure, which is convenient for dispersion of formed nanoparticles and to reduction of agglomeration.

Nanoparticles $\mathrm{Au}, \mathrm{MnO}_{2}, \mathrm{Fe}_{3} \mathrm{O}_{4}, \mathrm{CuO}, \mathrm{Co}_{3} \mathrm{O}_{4} \mathrm{NP}$ and $\mathrm{CeO}_{2}$ caused increased glutathione peroxidase activity (Wei \& Wang, 2013). Liu et al. (2012) have shown that stabilized nanoparticles of $\mathrm{MnO}_{2}$ imitate the activity of peroxidase, therefore they were started to be used in immunoassay for colorimetric measurements. New nanoparticles of $\mathrm{Co}_{9} \mathrm{~S}_{8}$ type with effective intrinsic peroxidase activity can be used for colorimetric ionisation of copper ions (Mu et al., 2018).

Ions of transition metals, such as $\mathrm{Fe}$, have peroxidase activity and can inactivate hydroxyl radicals using a general mechanism similar to Fenton's reaction (Singh, 2016; Gao et al., 2017). Khedri et al. (2018) mention that the peroxidase activity of chitosan coated $\mathrm{Fe}_{3} \mathrm{O}_{4} \mathrm{NPs}$ nanoparticles. Similarly to natural enzymes, the enzyme-mimetic activity of nanoparticles may be stimulated or inhibited by certain chemical compounds. Thus, nucleotides, in particular, AMP, can enhance the peroxidase activity of $\mathrm{Fe}_{3} \mathrm{O}_{4}$ nanoparticles at neutral $\mathrm{pH}$ by forming a complex (Yang et al., 2017). Inhibitors of this mimetic activity can be sodium azide, ascorbic acid and catecholamines (Liu et al., 2012). Liao et al. (2018) report that sulfide ions are capable of inhibiting peroxidase-like activity of copper nanoclusters (CuNCs).

It was determined that $\mathrm{TiO}_{2}$ nanoparticles demonstrated mimetic activity, can be incorporated into a photosensitive biocatalytic cascade, activate alkaline phosphatase, and subsequently peroxidase (Li et al., 2018). Brominated graphene (GBR) containing about $3 \%$ bromine had a mimetic peroxidase activity in relation to $3,3^{\prime}, 5,5^{\prime}$-tetramethylbenzidine (TMB). The optimum activity was observed at $\mathrm{pH} 4.48$ (Singh et al., 2016).

\section{Nanomaterials as phosphate mimetics}

Phosphatase catalyzes the hydrolysis of complex esters of phosphoric acid in living organisms. The function of phosphatase is maintaining the phosphate level required for various biochemical processes. Phosphatase is involved in biological processes such as cell proliferation, transduction of signals, metabolism, intercellular communication, etc. For the first time, phosphatase-like activity was studied in cerium nanoparticles (Kuchma et al., 2010). Nanoparticles of $\mathrm{SeO}_{2}$ exhibit phosphatasomimetic activity in relation to the hydrolysis of organic phosphate esters, and the dependence between of the reaction speed on the $\mathrm{pH}$ of the medium was determined (Singh, 2016). It is assumed that in the case of this reaction, splitting of phosphate and its adsorption on the surface of nanoparticles occur. According to Kozik et al. (2016), cerium dioxide nanoparticles are not complete phosphatase analogues, since the phosphate group binds to the surface of the nanoparticle irreversibly. Subsequently, cerium phosphate is desorbed, and the surface of nanoparticles is able to be involved in catalytic reactions again. Nanodispersive cerium dioxide is used for concentration and quantitative dephosphorylation of phosphoproteins (Jia et al., 2012). It also can stimulate phosphorylation of mitogen-active protein kinase in human bronchial epithelial cells (Beas2B), manifesting pro-oxidant properties (Park et al., 2008).

The activation of the nuclear transcription factor NF- $\kappa \mathrm{B}$ depends on phosphorylation of the protein-inhibitor of I $k \mathrm{~B} \alpha$-kinases (IKK) (Popov et al., 2017). NF- $\mathrm{kB}$ functions as one of the most important intracellular messengers which combines a variety of environmental signals with the expression of numerous cellular genes. NF- $\mathrm{KB}$ regulates a variety of biological processes: cell growth, their survival, tissue development, immune response and inflammatory processes. Disorders in regulation of 
signaling mechanisms which are based on NF- $\mathrm{KB}$ are associated with such severe human diseases as cancer, autoimmune diseases, chronic inflammation, metabolic disorders, diabetes and neurodegenerative diseases (Ghosh, 2007; Pushkarev et al., 2015).

The ability to purposefully regulate the activity of the factor NF- $\mathrm{KB}$ is promising for controlling and treating a large number of pathological processes in the cell. Research has shown that cerium dioxide nanoparticles inhibit phosphorylation of $\mathrm{I} \kappa \mathrm{B} \alpha$, thereby reducing the translocation of the p65 subunit, which occurs due to activation of NF- $\mathrm{KB}$ (Popov et al., 2017).

Nanoparticles with low ratios of the $\mathrm{Ce}^{3+} / \mathrm{Ce}^{4+}$ oxidation state demonstrate both mimetic activity of catalase and phosphatase (Dhall et al., 2017). The ability to manifest the activity of acid phosphatase was observed for Pt nanoparticles (Deng et al., 2017), and the activity of alkaline phosphatase simulates fullerene nanoparticles (Voeikov \& Yablonskaya, 2015). Reverse phosphorylation and dephosphorylation reactions are the basis of energy and signaling metabolism in the cells, and such molecular activity opens a new perspective in the evaluation and prediction of biological properties of nanoparticles (Celardo et al., 2011).

\section{Conclusions}

This paper demonstrates separate results on the study of the enzymatic activity of nanoparticles and their positive effects. However, there are a number of studies on the risks of their use (Bandas et al., 2015; Fu, 2014). As a result of the conducted analysis, we can state that nanoparticles have a large number of applications in various fields - biology, medicine, the food industry, etc. However, the development of new nanosystems raises a number of new questions. It has been found that nanoparticles are highly biologically active, which is determined by the polyfactor action, which needs to be determined. The interaction between nanoparticles and biological molecules, such as proteins, carbohydrates, and lipids, remain poorly studied. Practical application of nanoparticles in biology requires an integrated analysis of the duration of their stay in the organism and the need for targeted delivery to organs and tissues, which accelerates further spread (Grillone et al., 2017). Due to their mimetic properties, it is promising to use nanoparticles for the purpose of early diagnosis of dangerous diseases, development of fundamentally new methods and molecular instruments in therapy and surgery, as well as solving other biological and biotechnological problems. In future, research on this topic requires a safe, responsible and integrated approach with scientific research and assessments of possible medical-sanitary and environmental risks, which is the basis of the European Union policy in the field of nanotechnology (Regulation, 2012).

\section{References}

Amani, H., Habibey, R., Hajmiresmail, S. J., Latifi, S., Pazoki-Toroudi, H., \& Akhavan, O. (2017). Antioxidant nanomaterials in advanced diagnoses and treatments of ischemia reperfusion injuries. Journal of Materials Chemistry B, 5(48), 9452-9476.

Armstrong, D., Bharali, D. J., Armstrong, D., \& Bharali, D. (2013). Oxidative stress and nanotechnology. Methods and Protocols, 1028.

Baldim, V., Bedioui, F., Mignet, N., Margaill, I., \& Berret, J. F. (2018). The enzymelike catalytic activity of cerium oxide nanoparticles and its dependency on $\mathrm{Ce}^{3+}$ surface area concentration. Nanoscale, 10(15), 6971-6980.

Bandas, I. A., Krynytska, I. Y., Kulitska, M. I., \& Korda, M. M. (2015). Nanoparticles: Importance today, classification, use in medicine, toxicity. Medychna ta Klinichna Khimiya, 17(3), 123-129 (in Ukrainian).

BarathManiKanth, S., Kalishwaralal, K., Sriram, M., Pandian, S. R. K., Youn, H. S., Eom, S., \& Gurunathan, S. (2010). Anti-oxidant effect of gold nanoparticles restrains hyperglycemic conditions in diabetic mice. Journal of Nanobiotechnology, 8(1), 16.

Batinić-Haberle, I., Rebouças, J. S., \& Spasojević, I. (2010). Superoxide dismutase mimics: Chemistry, pharmacology, and therapeutic potential. Antioxidants and Redox Signaling, 13(6), 877-918.

Bhagat, S., Vallabani, N. S., Shutthanandan, V., Bowden, M., Karakoti, A. S., \& Singh, S. (2018). Gold core/Ceria shell-based redox active nanozyme mimicking the biological multienzyme complex phenomenon. Journal of Colloid and Interface Science, 513, 831-842.
Bityutskyy, V. S., Tsekhmistrenko, O. S., Tsekhmistrenko, S. I., Spyvack, M. Y., \& Shadura, U. M. (2017). Perspectives of cerium nanoparticles use in agriculture. The Animal Biology, 19(3), 9-17.

Cao, G. J., Jiang, X., Zhang, H., Croley, T. R., \& Yin, J. J. (2017). Mimicking horseradish peroxidase and oxidase using ruthenium nanomaterials. RSC Advances, 7(82), 52210-52217.

Celardo, I., Pedersen, J. Z., Traversa, E., \& Ghibelli, L. (2011). Pharmacological potential of cerium oxide nanoparticles. Nanoscale, 3(4), 1411-1420.

Chaudhry, Q., \& Castle, L. (2015). Safety assessment of nano- and microscale delivery vehicles for bioactive ingredients. Nanotechnology and Functional Foods: Effective Delivery of Bioactive Ingredients, 348-357.

Chekman, I. S., Horchakova, N. O. \& Simonov, P. V. (2017). Biologically active substances as nanostructures: A biochemical aspect. Klìnična Farmaciâ, 21(2), 15-22 (in Ukrainian).

Chen, H., Seiber, J. N., \& Hotze, M. (2014). ACS select on nanotechnology in food and agriculture: A perspective on implications and applications. Journal Agricultural and Food Chemistry, 62(6), 1209-1212.

Chen, S., Quan, Y., Yu, Y. L., \& Wang, J. H. (2017). Graphene quantum dot/silver nanoparticle hybrids with oxidase activities for antibacterial application. ACS Biomaterials Science and Engineering, 3(3), 313-321.

Chen, W., Chen, J., Feng, Y. B., Hong, L., Chen, Q. Y., Wu, L. F., Lin, X. H., \& Xia, X. H. (2012). Peroxidase-like activity of water-soluble cupric oxide nanoparticles and its analytical application for detection of hydrogen peroxide and glucose. Analyst, 137(7), 1706-1712.

Chen, Z., Yin, J. J., Zhou, Y. T., Zhang, Y., Song, L., Song, M., Hu, S., \& Gu, N. (2012). Dual enzyme-like activities of iron oxide nanoparticles and their implication for diminishing cytotoxicity. Acs Nano, 6(5), 4001-4012.

Cheng, H., Zhang, L., He, J., Guo, W., Zhou, Z., Zhang, X., Hie, S., \& Wei, H. (2016). Integrated nanozymes with nanoscale proximity for in vivo neurochemical monitoring in living brains. Analytical Chemistry, 88(10), 5489-5497.

Choleva, T. G., Gatselou, V. A., Tsogas, G. Z., \& Giokas, D. L. (2018). Intrinsic peroxidase-like activity of rhodium nanoparticles, and their application to the colorimetric determination of hydrogen peroxide and glucose. Microchimica Acta, 185(1), 22.

Cîrcu, M., Nan, A., Borodi, G., Liebscher, J., \& Turcu, R. (2016). Refinement of magnetite nanoparticles by coating with organic stabilizers. Nanomaterials, 6, 228.

Cormode, D. P., Gao, L., \& Koo, H. (2018). Emerging biomedical applications of enzyme-like catalytic nanomaterials. Trends in Biotechnology, 36(1), 15-29.

Cui, M., Zhao, Y., Wang, C., \& Song, Q. (2017). The oxidase-like activity of iridium nanoparticles, and their application to colorimetric determination of dissolved oxygen. Microchimica Acta, 184(9), 3113-3119.

Dalapati, R., Sakthivel, B., Ghosalya, M. K., Dhakshinamoorthy, A., \& Biswas, S. (2017). A cerium-based metal-organic framework having inherent oxidaselike activity applicable for colorimetric sensing of biothiols and aerobic oxidation of thiols. CrystEngComm, 19(39), 5915-5925.

Das, S., Dowding, J. M., Klump, K. E., McGinnis, J. F., Self, W., \& Seal, S. (2013). Cerium oxide nanoparticles: Applications and prospects in nanomedicine. Nanomedicine, 8(9), 1483-1508.

Deng, H. H., Lin, X. L., Liu, Y. H., Li, K. L., Zhuang, Q. Q., Peng, H. P., Liu, A. L., Xia, X. H., \& Chen, W. (2017). Chitosan-stabilized platinum nanoparticles as effective oxidase mimics for colorimetric detection of acid phosphatase. Nanoscale, 9(29), 10292-10300.

Dhall, A., Burns, A., Dowding, J., Das, S., Seal, S., \& Self, W. (2017). Characterizing the phosphatase mimetic activity of cerium oxide nanoparticles and distinguishing its active site from that for catalase mimetic activity using anionic inhibitors. Environmental Science: Nano, 4(8), 1742-1749.

Dong, Z., Luo, Q., \& Liu, J. (2012). Artificial enzymes based on supramolecular scaffolds. Chemical Society Reviews, 41(23), 7890-7908.

Dutta, A. K., Maji, S. K., Srivastava, D. N., Mondal, A., Biswas, P., Paul, P., \& Adhikary, B. (2012). Synthesis of FeS and FeSe nanoparticles from a single source precursor: A study of their photocatalytic activity, peroxidase-like behavior, and electrochemical sensing of $\mathrm{H}_{2} \mathrm{O}_{2}$. ACS Applied Materials \& Interfaces, 4(4), 1919-1927.

Estevez, A. Y., Stadler, B., \& Erlichman, J. S. (2017). In-vitro analysis of catalase-, oxidase- and SOD-mimetic activity of commercially available and customsynthesized cerium oxide nanoparticles and assessment of neuroprotective effects in a hippocampal brain slice model of ischemia. The FASEB Journal, 31(1 Supplement), 693-695.

Esumi, K., Takei, N., \& Yoshimura, T. (2003). Antioxidant-potentiality of goldchitosan nanocomposites. Colloids and Surfaces B: Biointerfaces, 32, 117-123.

Fa, M., Yang, D., Gao, L., Zhao, R., Luo, Y., \& Yao, X. (2018). The effect of AuNP modification on the antioxidant activity of $\mathrm{CeO}_{2}$ nanomaterials with different morphologies. Applied Surface Science, 2018, e277.

Faisal, M., Saquib, Q., Alatar, A. A., Al-Khedhairy, A. A., Hegazy, A. K., \& Musarrat, J. (2013). Phytotoxic hazards of NiO-nanoparticles in tomato: A study on mechanism of cell death. Journal of Hazardous Materials, 250, 318-332. 
Fan, Y., \& Huang, Y. (2012). The effective peroxidase-like activity of chitosanfunctionalized $\mathrm{CoFe}_{2} \mathrm{O}_{4}$ nanoparticles for chemiluminescence sensing of hydrogen peroxide and glucose. Analyst, 137(5), 1225-1231.

Farhangi-Abriz, S., \& Torabian, S. (2018). Nano-silicon alters antioxidant activities of soybean seedlings under salt toxicity. Protoplasma, 2018, 1-10.

$\mathrm{Fu}, \mathrm{P}$. P. (2014). Introduction to the special issue: Nanomaterials-toxicology and medical applications. Journal of Food and Drug Analysis, 22(1), 1-2.

Gao, L., Fan, K., \& Yan, X. (2017). Iron oxide nanozyme: A multifunctional enzyme mimetic for biomedical applications. Theranostics, 7(13), 3207-3227.

Garai-Ibabę G., Möller M., Saa, L., Grinyte, R., \& Pavlov, V. (2014). Peroxidasemimicking DNAzyme modulated growth of CdS nanocrystalline structures in situ through redox reaction: Application to development of genosensors and aptasensors. Analytical Chemistry, 86, 10059-10064.

Ghosh, S. (2006). Handbook of transcription factor NF-kappaB. CRC Press.

Gil, D., Rodriguez, J., Ward, B., Vertegel, A., Ivanov, V., \& Reukov, V. (2017). Antioxidant activity of SOD and catalase conjugated with nanocrystalline ceria. Bioengineering, 4(1), 18

Gordon, A. T., Lutz, G. E., Boninger, M. L., \& Cooper, R. A. (2007). Introduction to nanotechnology: Potential applications in physical medicine and rehabilitation. American Journal of Physical Medicine and Rehabilitation, 86(3), 225-241.

Grillone, A., Li, T., Battaglini, M., Scarpellini, A., Prato, M., Takeoka, S., \& Ciofani, G. (2017). Preparation, characterization, and preliminary in vitro testing of nanoceria-loaded liposomes. Nanomaterials, 7(9), 276.

Grinko, A. M., Brichka, A. V., Bakalinska, O. M., Brichka, S. Y., \& Kartel, M. T. (2015). Hydrogen peroxide decomposition by nanocomposites kaolin clay nanoceria. Poverkhnost', 7, 274-284 (in Ukrainian).

Grulke, E., Reed, K., Beck, M., Huang, X., Cormack, A., \& Seal, S. (2014). Nanoceria: Factors affecting its pro- and antioxidant properties. Environmental Science: Nano, 1(5), 429-444.

Guo, L., Huang, K., \& Liu, H. (2016). Biocompatibility selenium nanoparticles with an intrinsic oxidase-like activity. Journal of Nanoparticle Research, 18(3), 74.

Guo, Y., Wang, H., Ma, X., Jin, J., Ji, W., Wang, X., Song, W., Zhao, B., \& He, C. (2017). Fabrication of $\mathrm{Ag}-\mathrm{Cu}_{2} \mathrm{O}$ /reduced graphene oxide nanocomposites as surface-enhanced raman scattering substrates for in situ monitoring of peroxidase-like catalytic reaction and biosensing. ACS Applied Materials and Interfaces, 9(22), 19074-19081.

He, W., Liu, Y., Yuan, J., Yin, J. J., Wu, X., Hu, X., Zhang, K., Liu, J., Chen, C., Ji, Y., \& Guo, Y. (2011). Au@Pt nanostructures as oxidase and peroxidase mimetics for use in immunoassays. Biomaterials, 32(4), 1139-1147.

He, W., Wamer, W., Xia, Q., Yin, J. J., \& Fu, P. P. (2014). Enzyme-like activity of nanomaterials. Journal of Environmental Science and Health, Part C, 32(2), 186-211.

Heckert, E. G., Seal, S., \& Self, W. T. (2008). Fenton-like reaction catalyzed by the rare earth inner transition metal cerium. Environmental Science and Technology, 42(13), 5014-5019.

Hosnedlova, B., Kepinska, M., Skalickova, S., Fernandez, C., Ruttkay-Nedecky, B., Peng, Q., Baron, M., Melcova, M., Opatrilova, R., Zidkova, J., Bjørklund, G., Sochor, J., \& Bjørklund, G. (2018). Nano-selenium and its nanomedicine applications: A critical review. International Journal of Nanomedicine, 13, 2107-2128.

Huang, B., Zhang, J., Hou, J., \& Chen, C. (2003). Free radical scavenging efficiency of Nano-Se in vitro. Free Radical Biology and Medicine, 35(7), 805-813.

Jia, H., Yang, D., Han, X., Cai, J., Liu, H., \& He, W. (2016). Peroxidase-like activity of the $\mathrm{Co}_{3} \mathrm{O}_{4}$ nanoparticles used for biodetection and evaluation of antioxidant behavior. Nanoscale, 8(11), 5938-5945.

Jia, W., Andaya, A., \& Leary, J. A. (2012). Novel mass spectrometric method for phosphorylation quantification using cerium oxide nanoparticles and tandem mass tags. Analytical Chemistry, 84(5), 2466-2473.

Jiang, B., Duan, D., Gao, L., Zhou, M., Fan, K., Tang, Y., Xi, J., Bi, Y., Tong, Z. Gao, G. F., Xie, N., Tang, A., Nie, G., Liang M., \& Xie, N. (2018). Standardized assays for determining the catalytic activity and kinetics of peroxidaselike nanozymes. Nature Protocols, 1.

Jiang, L., Yuan, R., Chai, Y., Yuan, Y., Bai, L., \& Wang, Y. (2013). An ultrasensitive electrochemical aptasensor for thrombin based on the triplex-amplification of hemin/G-quadruplex horseradish peroxidase-mimicking DNAzyme and horseradish peroxidase decorated FeTe nanorods. Analyst, 138(5), 1497-1503.

Kajita, M., Hikosaka, K., litsuka, M., Kanayama, A., Toshima, N., \& Miyamoto, Y. (2007). Platinum nanoparticle is a useful scavenger of superoxide anion and hydrogen peroxide. Free Radical Research, 41, 615-626.

Khedri, B., Shahanipour, K., Fatahian, S., \& Jafary, F. (2018). Preparation of chitosan-coated $\mathrm{Fe}_{3} \mathrm{O}_{4}$ nanoparticles and assessment of their effects on enzymatic antioxidant system as well as high-density lipoprotein/low-density lipoprotein lipoproteins on wistar rat. Biomedical and Biotechnology Research Journal, 2(1), 68

Kim, C. K., Kim, T., Choi. I.-Y., Soh, M., Kim, D., Kim, Y.-J., Jang, H., Yang, H.-S., Kim, J. Y., Park, H. K., Park, S. P., Park, S., Yu, T., Yoon, B.-W., Lee,
S.-H., Hyeon, T. (2012). Ceria nanoparticles that can protect against ischemic stroke. Angewandte Chemie International Edition, 51, 11039-11043.

Kim, J., Takahashi, M., Shimizu, T., Shirasawa, T., Kajita, M., Kanayama, A., \& Miyamoto, Y. (2008). Effects of a potent antioxidant, platinum nanoparticle, on the lifespan of Caenorhabditis elegans. Mechanisms of Ageing and Development, 129(6), 322-331.

Korsvik, C., Patil, S., Seal, S., \& Self, W. T. (2007). Superoxide dismutase mimetic properties exhibited by vacancy engineered ceria nanoparticles. Chemical Communications, (10), 1056-1058.

Kozik, V. V., Shcherbakov, A. B., Ivanova, O. S., Spivak, N. Y., \& Ivanov, V. K. (2016). Synthesis and biomedical applications of nanodispersed cerium dioxide. Izdatel'skiy Dom Tomskogo universiteta, Tomsk.

Kuchma, M. H., Komanski, C. B., Colon, J., Teblum, A., Masunov, A. E., Alvarado, B., Badu, S., Seal, S., Summy, J., \& Baker, C. H. (2010). Phosphate ester hydrolysis of biologically relevant molecules by cerium oxide nanoparticles. Nanomedicine: Nanotechnology, Biology and Medicine, 6(6), 738-744.

Lee, S. S., Song, W., Cho, M., Puppala, H. L., Nguyen, P., Zhu, H., Segatori, L., \& Colvin, V. L. (2013). Antioxidant properties of cerium oxide nanocrystals as a function of nanocrystal diameter and surface coating. ACS Nano, 7(11), 9693-9703.

Li, H., Wang, T., Wang, Y., Wang, S., Su, P., \& Yang, Y. (2018). Intrinsic tripleenzyme mimetic activity of $\mathrm{V}_{6} \mathrm{O}_{13}$ nanotextiles: Mechanism investigation and colorimetric and fluorescent detections. Industrial and Engineering Chemistry Research, 57(6), 2416-2425.

Li, J., Schiavo, S., Xiangli, D., Rametta, G., Miglietta, M. L., Oliviero, M., Changwen, W., \& Manzo, S. (2018). Early ecotoxic effects of ZnO nanoparticle chronic exposure in Mytilus galloprovincialis revealed by transcription of apoptosis and antioxidant-related genes. Ecotoxicology, 2018, 1-16.

Li, M., \& Zhang, C. (2016). $\gamma-\mathrm{Fe}_{2} \mathrm{O}_{3}$ nanoparticle-facilitated bisphenol A degradation by white rot fungus. Science Bulletin, 61(6), 468-472.

Li, P., Cao, G. X., Liu, Q., Guo, Y. Y., Dong, Y., Li, Z., \& Wang, G. L. (2018) A novel strategy for amplified probing versatile biomolecules through a photoswitchable biocatalytic cascade. Sensors and Actuators B: Chemical, $262,110-117$.

Liao, H., Hu, L., Zhang, Y., Yu, X., Liu, Y., \& Li, R. (2018). A highly selective colorimetric sulfide assay based on the inhibition of the peroxidase-like activity of copper nanoclusters. Microchimica Acta, 185(2), 143

Lin, Y., Ren, J., \& Qu, X. (2014). Nano-gold as artificial enzymes: Hidden talents. Advanced Materials, 26(25), 4200-4217.

Liu, B., Sun, Z., Huang, P. J. J., \& Liu, J. (2015). Hydrogen peroxide displacing DNA from nanoceria: Mechanism and detection of glucose in serum. Journal of the American Chemical Society, 137(3), 1290-1295.

Liu, C. H., Yu, C. J., \& Tseng, W. L. (2012). Fluorescence assay of catecholamines based on the inhibition of peroxidase-like activity of magnetite nanoparticles. Analytica Chimica Acta, 745, 143-148.

Liu, X., Wang, Q., Zhao, H., Zhang, L., Su, Y., \& Lv, Y. (2012). BSA-templated $\mathrm{MnO}_{2}$ nanoparticles as both peroxidase and oxidase mimics. Analyst 137(19), 4552-4558.

Liu, Y., Wu, H., Chong, Y., Wamer, W. G., Xia, Q., Cai, L., Nie, Z., Fu, P. P., \& Yin, J. J. (2015). Platinum nanoparticles: Efficient and stable catechol oxidase mimetics. ACS Applied Materials and Interfaces, 7(35), 19709-19717.

Lu, L., Wang, X., Xiong, C., \& Yao, L. (2015). Recent advances in biological detection with magnetic nanoparticles as a useful tool. Science China Chemistry, 58(5), 793-809.

Lu, X., Mestres, G., Singh, V. P., Effati, P., Poon, J. F., Engman, L., \& Ott, M. K. (2017). Selenium-and tellurium-based antioxidants for modulating inflamemation and effects on osteoblastic activity. Antioxidants, 6(1), 13.

Luo, W., Li, Y. S., Yuan, J., Zhu, L., Liu, Z., Tang, H., \& Liu, S. (2010). Ultrasensitive fluorometric determination of hydrogen peroxide and glucose by using multiferroic $\mathrm{BiFeO}_{3}$ nanoparticles as a catalyst. Talanta, 81(3), 901-907.

Lushchak, V. I. (2015). Free radicals, reactive oxygen species, oxidative stresses and their classifications. The Ukrainian Biochemical Journal, 87(6), 11-18.

McCormack, R. N., Mendez, P., Barkam, S., Neal, C. J., Das, S., \& Seal, S. (2014). Inhibition of nanoceria's catalytic activity due to $\mathrm{Ce}^{3+}$ site-specific interaction with phosphate ions. The Journal of Physical Chemistry C, 118(33), 18992 19006.

Moglianetti, M., De Luca, E., Pedone, D., Marotta, R., Catelani, T., Sartori, B., Amenitsch, H., Retta, S. F., \& Pompa, P. P. (2016). Platinum nanozymes recover cellular ROS homeostasis in an oxidative stress-mediated disease model. Nanoscale, 8(6), 3739-3752.

Morry, J., Ngamcherdtrakul, W., \& Yantasee, W. (2017). Oxidative stress in cancer and fibrosis: Opportunity for therapeutic intervention with antioxidant compounds, enzymes, and nanoparticles. Redox Biology, 11, 240-253.

Mu, J., Li, J., Zhao, X., Yang, E. C., \& Zhao, X. J. (2018). Novel urchin-like Cogos nanomaterials with efficient intrinsic peroxidase-like activity for colorimetric sensing of copper (II) ion. Sensors and Actuators B: Chemical, 258, 32-41. 
Naganuma, T. (2017). Shape design of cerium oxide nanoparticles for enhancement of enzyme mimetic activity in therapeutic applications. Nano Research, 10(1), 199-217.

Nelson, B. C., Johnson, M. E., Walker, M. L., Riley, K. R., \& Sims, C. M. (2016) Antioxidant cerium oxide nanoparticles in biology and medicine. Antioxidants, 5(2), 15 .

Pandey, V. P., Awasthi, M., Singh, S., Tiwari, S., \& Dwivedi, U. N. (2017). A comprehensive review on function and application of plant peroxidases. Biochemistry and Analytical Biochemistry, 6, 308 .

Park, E. J., Choi, J., Park, Y. K., \& Park, K. (2008). Oxidative stress induced by cerium oxide nanoparticles in cultured BEAS-2B cells. Toxicology, 245(1-2), 90-100.

Paul, S., Saikia, J., Samdarshi, S., \& Konwar, B. (2009). Investigation of antioxidant property of iron oxide particlesby 1'-1' diphenylpicryl-hydrazyle (dpph) method. Journal of Magnetism and Magnetic Materials, 321, 3621-3623.

Popov, A. L., Shcherbakov, A. B., Zholobak, N. M., Baranchikov, A. Y., \& Ivanov, V. K. (2017). Cerium dioxide nanoparticles as third-generation enzymes (nanozymes). Nanosystems: Physics, Chemistry, Mathematics, 8(6), 760-784.

Pratsinis, A., Kelesidis, G. A., Zuercher, S., Krumeich, F., Bolisetty, S., Mezzenga, R., Leroux, J. C., \& Sotiriou, G. A. (2017). Enzyme-mimetic antioxidant luminescent nanoparticles for highly sensitive hydrogen peroxide biosensing. ACS Nano, 11(12), 12210-12218.

Pushkarev, V. M., Kovzun, O. I., Pushkarev, V. V., Huda, B. B., \& Tronko, N. D. (2015). Chronic inflammation and cancer. Role of nuclear factor NF- $\kappa \mathrm{B}$ (review of literature and own data). Journal of the National Academy of Medical Sciences of Ukraine, 21(3-4), 287-298.

Regulation, E. U. (2012). No 528/2012 of the European Parliament and of the Council of 22 May 2012 concerning the making available on the market and use of biocidal products. Official Journal of the European Union L, 167.

Saikia, J. P., Paul, S., Konwar, B. K., \& Samdarshi, S. K. (2010). Nickel oxide nanoparticles: A novel antioxidant. Colloids and Surfaces B: Biointerfaces, 78, 146-148

Samuel, E. L. G., Duong, M. T., Bitner, B. R., Marcano, D. C., Tour, J. M., \& Kent, T. A. (2014). Hydrophilic carbon clusters as therapeutic, high-capacity antioxidants. Trends in Biotechnology, 32, 501-505.

Sandhir, R., Yadav, A., Sunkaria, A., \& Singhal, N. (2015). Nano-antioxidants: An emerging strategy for intervention against neurodegenerative conditions. Neurochemistry International, 89, 209-226.

Schubert, D., Dargusch, R., Raitano, J., \& Chan, S.-W. (2006). Cerium and yttrium oxide nanoparticles are neuroprotective. Biochemical and Biophysical Research Communications, 342, 86-91.

Shah, S. T., A Yehya, W., Saad, O., Simarani, K., Chowdhury, Z., A Alhadi, A., \& Al-Ani, L. A. (2017). Surface functionalization of iron oxide nanoparticles with gallic acid as potential antioxidant and antimicrobial agents. Nanomaterials, $7(10), 306$.

Sharpe, E., Andreescu, D., \& Andreescu, S. (2011). Artificial nanoparticle antioxidants. ACS Symposium Series, 1083, 235-253.

Shcherbakov, A. B., Zholobak, N. M., Ivanov, V. K., Tretyakov, Y. D., \& Spivak, N. Y. (2011). Nanomaterials based on the nanocrystalline ceric dioxode: Properties and use perspectives in biology and medicine. Biotechnologia Acta, 4(1), 9-28 (in Russian).

Shin, D. S., Di Donato, M., Barondeau, D. P., Hura, G. L., Hitomi, C., Berglund J. A., Getzoff, E. D., Cary, S. C., \& Tainer, J. A. (2009). Superoxide dismutase from the eukaryotic thermophile Alvinella pompejana: Structures, stability, mechanism, and insights into amyotrophic lateral sclerosis. Journal of Molecular Biology, 385(5), 1534-1555.

Sims, C. M., Hanna, S. K., Heller, D. A., Horoszko, C. P., Johnson, M. E., Bustos, A. R. M., Reipa, V., Riley, K. R., \& Nelson, B. C. (2017). Redox-active nanomaterials for nanomedicine applications. Nanoscale, 9(40), 15226-15251.

Singh, S. (2016). Cerium oxide based nanozymes: Redox phenomenon at biointerfaces. Biointerphases, 11(4), 04B202.

Singh, S. (2017). Catalytically active nanomaterials: Artificial enzymes of next generation. Nanoscience and Technology, 5(1), 1-6.

Singh, S., Mitra, K., Shukla, A., Singh, R., Gundampati, R. K., Misra, N., Maiti, P., \& Ray, B. (2016). Brominated graphene as mimetic peroxidase for sulfide ion recognition. Analytical Chemistry, 89(1), 783-791.

Singh, S., Singh, M., Mitra, K., Singh, R., Gupta, S. K. S., Tiwari, I., \& Ray, B. (2017). Electrochemical sensing of hydrogen peroxide using brominated graphene as mimetic catalase. Electrochimica Acta, 258, 1435-1444.

Soares, C., Branco-Neves, S., de Sousa, A., Azenha, M., Cunha, A., Pereira, R., \& Fidalgo, F. (2018). $\mathrm{SiO}_{2}$ nanomaterial as a tool to improve Hordeum vulgare $\mathrm{L}$. tolerance to nano-NiO stress. Science of the Total Environment, 622, 517-525.

Song, Y., Zhao, M., Li, H., Wang, X., Cheng, Y., Ding, L., Fan, S., \& Chen, S. (2018). Facile preparation of urchin-like $\mathrm{NiCo}_{2} \mathrm{O}_{4}$ microspheres as oxidase mimetic for colormetric assay of hydroquinone. Sensors and Actuators B Chemical, 255, 1927-1936.
Su, L., Feng, J., Zhou, X., Ren, C., Li, H., \& Chen, X. (2012). Colorimetric detection of urine glucose based $\mathrm{ZnFe}_{2} \mathrm{O}_{4}$ magnetic nanoparticles. Analytical Chemistry, 84(13), 5753-5758.

Sun, L., Ding, Y., Jiang, Y., \& Liu, Q. (2017). Montmorillonite-loaded ceria nanocomposites with superior peroxidase-like activity for rapid colorimetric detection of $\mathrm{H}_{2} \mathrm{O}_{2}$. Sensors and Actuators B: Chemical, 239, 848-856.

Szekeres, M., Toth, I. Y., Illes, E., Hajdu, A., Zupko, I., Farkas, K., Oszlanczi, G. Tiszlavicz, L., \& Tombacz, E. (2013). Chemical and colloidal stability of carboxylated core-shell magnetite nanoparticles designed for biomedical applications. International Journal of Molecular Sciences, 14, 14550-14574.

Toth, I. Y., Szekeres, M., Turcu, R., Saringer, S., Illes, E., Nesztor, D., \& Tombacz, E. (2014). Mechanism of in situ surface polymerization of gallic acid in an environmental-inspired preparation of carboxylated core-shell magnetite nanoparticles. Langmuir, 30, 15451-15461.

Tsai, Y. Y., Oca-Cossio, J., Agering, K., Simpson, N. E., Atkinson, M. A., Wasserfall, C. H., Constantinidis, I., \& Sigmund, W. (2007). Novel synthesis of cerium oxide nanoparticles for free radical scavenging. Nanomedicine, 2(3), 325-332.

Tsekhmistrenko, O. S., Tsekhmistrenko, S. I., Bityutskyy, V. S., Melnichenko, O. M., \& Oleshko, O. A. (2018). Biomimetic and antioxidant activity of nanocrystalline cerium dioxide. Svit Medytsyny ta Biolohii, 63(1), 196-201.

van Bloois, E., Pazmiño, D. E. T., Winter, R. T., \& Fraaije, M. W. (2010). A robust and extracellular heme-containing peroxidase from Thermobifida fusca as prototype of a bacterial peroxidase superfamily. Applied Microbiology and Biotechnology, 86(5), 1419-1430.

Verma, A. K. (2014). Anti-oxidant activities of biopolymeric nanoparticles: Boon or bane! Journal of Pharmacy Research, 8, 871-876.

Vernekar, A. A., Das, T., Ghosh, S., \& Mugesh, G. (2016). A remarkably efficient $\mathrm{MnFe}_{2} \mathrm{O}_{4}$-based oxidase nanozyme. Chemistry - An Asian Journal, 11, 72-76.

Vineh, M. B., Saboury, A. A., Poostchi, A. A., Rashid, A. M. \& Parivar, K. (2017). Stability and activity improvement of horseradish peroxidase by covalent immobilization on functionalized reduced graphene oxide and biodegradetion of high phenol concentration. International Journal of Biological Macromolecules, 17, 32776-32779.

Voeikov, V. L., \& Yablonskaya, O. I. (2015). Stabilizing effects of hydrated fullerenes $\mathrm{C}_{60}$ in a wide range of concentrations on luciferase, alkaline phosphatese, and peroxidase in vitro. Electromagnetic Biology and Medicine, 34(2), 160-166.

Wang, G., Zhang, J., He, X., Zhang, Z., \& Zhao, Y. (2017). Ceria nanoparticles as enzyme mimetics. Chinese Journal of Chemistry, 35(6), 791-800.

Wang, H., Li, S., Si, Y., Zhang, N., Sun, Z., Wu, H., \& Lin, Y. (2014). Platinum nanocatalysts loaded on graphene oxide-dispersed carbon nanotubes with greatly enhanced peroxidase-like catalysis and electrocatalysis activities. Nanoscale, 6(14), 8107-8116.

Wang, H., Zhang, J., \& Yu, H. (2007). Elemental selenium at nano size possesses lower toxicity without compromising the fundamental effect on selenoenzymes: Comparison with selenomethionine in mice. Free Radical Biology and Medicine, 42(10), 1524-1533.

Wang, K., Song, J., Duan, X., Mu, J., \& Wang, Y. (2017). Perovskite LaCoO nanoparticles as enzyme mimetics: Their catalytic properties, mechanism and application in dopamine biosensing. New Journal of Chemistry, 41(16), $8554-8560$.

Wang, Q., Zhang, L., Shang, C., Zhang, Z., \& Dong, S. (2016). Triple-enzyme mimetic activity of nickel-palladium hollow nanoparticles and their application in colorimetric biosensing of glucose. Chemical Communications, 52(31), 5410-5413

Wei, H., \& Wang, E. (2013). Nanomaterials with enzyme-like characteristics (nanozymes): Next-generation artificial enzymes. Chemical Society Reviews, 42(14), 6060-6093

$\mathrm{Xu}, \mathrm{C} ., \& \mathrm{Qu}, \mathrm{X}$. (2014). Cerium oxide nanoparticle: A remarkably versatile rare earth nanomaterial for biological applications. NPG Asia Materials, 6(3), e90.

Yan, X., Song, Y., Wu, X., Zhu, C., Su, X., Du, D., \& Lin, Y. (2017). Oxidasemimicking activity of ultrathin $\mathrm{MnO}_{2}$ nanosheets in colorimetric assay of acetylcholinesterase activity. Nanoscale, 9(6), 2317-2323.

Yang, Y. C., Wang, Y. T., \& Tseng, W. L. (2017). Amplified peroxidase-like activity in iron oxide nanoparticles using adenosine monophosphate: Application to urinary protein sensing. ACS Applied Materials and Interfaces, 9(11) 10069-10077.

Yang, Y., Mao, Z., Huang, W., Liu, L., Li, J., Li, J., \& Wu, Q. (2016). Redox enzyme-mimicking activities of $\mathrm{CeO}_{2}$ nanostructures: Intrinsic influence of exposed facets. Scientific Reports, 6, 35344.

Yao, J., Cheng, Y., Zhou, M., Zhao, S., Lin, S., Wang, X., Wu, J., Li, S., \& Wei, H. (2018). ROS scavenging $\mathrm{Mn}_{3} \mathrm{O}_{4}$ nanozymes for in vivo anti-inflammation. Chemical Science, 9(11), 2927-2933.

Zhang, X., He, S., Chen, Z., \& Huang, Y. (2013). $\mathrm{CoFe}_{2} \mathrm{O}_{4}$ nanoparticles as oxidase mimic-mediated chemiluminescence of aqueous luminol for sulfite in white wines. Journal of Agricultural and Food Chemistry, 61(4), 840-847. 
Zhao, J., Dong, W., Zhang, X., Chai, H., \& Huang, Y. (2018). FeNPs@ $\mathrm{Co}_{3} \mathrm{O}_{4}$ hollow nanocages hybrids as effective peroxidase mimics for glucose biosensing. Sensors and Actuators B: Chemical, 263, 575-584.

Zhao, M., Huang, J., Zhou, Y., Pan, X., He, H., Ye, Z., \& Pan, X. (2013). Controlled synthesis of spinel $\mathrm{ZnFe}_{2} \mathrm{O}_{4}$ decorated $\mathrm{ZnO}$ heterostructures as peroxidase mimetics for enhanced colorimetric biosensing. Chemical Communications, 49(69), 7656-7658
Zheng, W., Zou, H. F., Lv, S. W., Lin, Y. H., Wang, M., Yan, F., Sheng, Y., Song, Y. H., Chen, J., \& Zheng, K. Y. (2017). The effect of nano- $\mathrm{TiO}_{2}$ photocatalysis on the antioxidant activities of $\mathrm{Cu}, \mathrm{Zn}-\mathrm{SOD}$ at physiological $\mathrm{pH}$. Journal of Photochemistry and Photobiology B: Biology, 174, 251-260.

Zhu, A., Sun, K., \& Petty, H. (2012). Titanium doping reduces superoxide dismutase activity, but not oxidase activity, of catalytic $\mathrm{CeO}_{2}$ nanoparticles. Inorganic Chemistry Communications, 15, 235-237. 